\title{
Biojóias - transforming ideas in sustainable business
}

\section{Paula Roberta Viana de Menezes ${ }^{1}$, Regina Celi S. Muller², Claudio Nahum Alves ${ }^{3}$}

\author{
12,3, Programa de Pós-Graduação em Ciência e Meio Ambiente do Instituto de Ciências Exatas e Naturais da Universidade Federal do \\ Pará (PPGCMA/ICEN/UFPA). Bairro Guamá. CEP: 66075-110. Caixa Postal 479. PABX +55 9132017000. Belém - Pará - Brasil.
}

Email: paulamenezesbraga@hotmail.com; reginamuller60@gmail.com; nahum@ufpa.com

Received: September $27^{\text {th }}, 2017$.

Accepted:. September $29^{\text {th }}, 2017$.

Published:. December 13 ${ }^{\text {th }}, 2017$.

Copyright (02016 by authors and Institute of Technology Galileo of Amazon (ITEGAM).This work is licensed under the CreativeCommons Attribution InternationalLicense (CC BY 4.0).

http://creativecommons.org/licenses/by/4.0/

\section{ABSTRACT}

Entrepreneurship is a term that is usually associated with private investment to assist in the fight against unemployment, but must be seen also as a new way of acting in an environment where it is possible to identify new ways of acting, to develop new knowledge and identify new opportunities. This is the focus of research will develop, because what if you want to study is the making of biojoias using as raw material the lump of Tucuman, so this research will have in one of your objects describe the quality on the transformation of the lump of Tucuman, typically Amazon fruit, in biojoias as a source of entrepreneurship. This line of business professionals create and offer craft products using various types of raw materials, specifically in this case, the seed of Astrocaryum vulgare and finish their products so that they reflect the local culture and identify your author. They are also responsible for the marketing of their products as well as the management of your business. The methodology includes theoretical and field research. Field research will use the techniques of observation and questionnaire. The questionnaire will have the purpose to analyze the use of seed of Astrocaryum vulgare, from collection to processing into raw material for biojoias. The results indicate that the bio-industry, today, is growing due to the spread of ideas of innovative entrepreneurship for local development and new income generation. He was identified by the study of the flow of tourists in the handicraft of Avenida Eduardo Ribeiro and abundant raw materials to promote the development of the activity.

Keywords: Entrepreneurship; Seeds of Tucuman; Biojoias.

\section{Biojóias - transformando ideias em negócio sustentável}

\section{RESUMO}

Empreendedorismo é um termo que geralmente é associado a investimentos privados que auxiliam no combate ao desemprego, porém deve ser visto também, como uma nova forma de agir em um ambiente onde é possível identificar formas de desenvolver novos conhecimentos proporcionando assim, novas oportunidades. O presente trabalho tem como objetivo demonstrar as vantagens do empreendedorismo sustentável na produção de biojoias utilizando a semente de tucumã como oportunidade rentável. A presente pesquisa é de caráter quantiqualitativo e foi desenvolvida com 52 artesãos, pequenos empreendedores que fabricam artesanatos na Associação da Feira de Artesanato e produtos do amazonas localizada na Avenida Eduardo Ribeiro, Manaus-AM. A eficácia e qualidade da produção das biojoias foi avaliada através de observação participante e aplicação de questionário. Com os resultados obtidos, pode-se comprovar que a produção de Biojoias torna-se a cada dia uma atividade lucrativa e rentável para a população que desenvolve essas atividades e isso pode ser comprovado com os dados estatísticos onde $92 \%$ dos pesquisados afirmaram que conseguem uma renda acima de $70 \%$ mensal para sustento da família. Dessa forma, verificou-se que além de valorizar e preservar a cultura local esta pratica contribui com o meio ambiente e ainda é lucrativa, prazerosa e essencial para a confecção de biojoias na cidade de Manaus-AM.

Palavras-chave: Empreendedorismo; Sementes de Tucumã; Biojoias. 


\section{INTRODUÇÃO}

Os recursos naturais da Amazônia há muito tempo vêm atraindo a atenção tanto no âmbito nacional quanto internacional, não apenas pelos atrativos, como pela escassez que seu uso inapropriado pode causar ao planeta. Há muito tempo esses recursos são explorados para comercialização sem nenhuma preocupação com o ambiente das futuras gerações.

A busca pelo desenvolvimento dessa região é bastante estudada hoje, mas não se torna algo tão fácil, uma vez que se deve procurar o desenvolvimento para a região sem que possa trazer agressão ao meio-ambiente. É partindo desta questão que muitos empreendedores buscam alternativas de desenvolvimento sustentável.

Sobre isso [1], nos mostram que há muitas formas de gerar o desenvolvimento econômico de uma localidade usufruindo conscientemente da natureza. $\mathrm{O}$ estado do Amazonas é um dos locais onde existe a intensa produção de artigos feitos com materiais naturais. E essa produção proporciona aos moradores dessas localidades muitas oportunidades de negócios, na exploração da fruta tucumã, utilizando seu caroço, o transformando em belas joias.

O Amazonas se destaca nesse contexto por ser o maior estado do Brasil, e possuir uma imensa área de reserva florestal com uma grande riqueza de fauna e flora, possibilitando alternativas de desenvolvimento sustentável, mas que infelizmente está sendo ameaçada pela ação desordenada do homem, evidenciando a necessidade de novas discussões sobre políticas públicas relacionadas ao desenvolvimento lucrativo e sustentável nessa região.

Para um processo sustentável, o bem-estar do homem é objetivamente necessário, pois é ele o principal responsável por implementar as demais ações de sustentabilidade que garantirão o futuro para a sua e para as novas gerações. [1].

Dessa forma a produção de biojoias com a utilização do caroço de Tucumán se apresenta como uma excelente alternativa para o desenvolvimento de atividade lucrativa e ambientalmente sustentável.

[2] nos fala algo muito interessante quando afirma que as políticas públicas existentes sobre meio ambiente precisam sair do papel, e tornar-se efetivas para que cada vez mais o desenvolvimento de atividades como esta aqui proposta, aconteça de forma satisfatória, onde os empreendedores 'verdes', aqui pesquisados demonstram todas as suas habilidades, onde estes nos mostram que é totalmente possível o desenvolvimento de atividades sustentáveis com lucratividade.

A proposta desenvolvida nesta pesquisa parte do pressuposto que a atividade artesanal com sementes ornamentais no Brasil é um campo aberto, repleto de possibilidades, principalmente através do design.

Um dos maiores mercados em que as sementes ornamentais são aplicadas é o da Biojoia, inclusive com abrangência internacional. Observando os produtos no mercado, e os trabalhos mais diferenciados presentes na moda/joalheria, descobriu-se um campo aberto para o foco da presente pesquisa.

Partindo dessa visão de unir negócios com recursos naturais, visto que há um segmento no mercado que vem crescendo com bastante potencial no Estado que é o das biojoias, muitos são os municípios que possuem essa produção presente em sua economia local e que se destaca como fator gerador de renda. Tais produtos interessam ao mercado consumidor nacional e internacional. [1].

Desse modo, o presente trabalho tem como objetivo principal demonstrar as vantagem do empreendedorismo sustentável na produção de biojoias utilizando a semente de tucumã como oportunidade rentável aos produtores-artesoes que desenvolvem e comercializam seus produtos na avenida Eduardo Ribeiro, Centro da cidade de Manaus-AM.

\section{EMPREENDEDORISMO}

A palavra empreendedor (entrepreneur) tem origem francesa e quer dizer aquele que assume riscos e começa algo de novo. Disposição ou capacidade de idealizar, coordenar e realizar projetos, serviços, negócios. Iniciativa de implementar novos negócios ou mudanças em empresas já existentes, alterações que envolvem inovação e riscos. Conjunto de conhecimentos relacionados a essa forma de agir.

Segundo Robert Menezes, professor de empreendedorismo da UFCG, o empreendedorismo pode ser compreendido como a arte de fazer acontecer com criatividade e motivação. Consiste no prazer de realizar com sinergismo e inovação qualquer projeto pessoal ou organizacional, em desafio permanente às oportunidades e riscos. É assumir um comportamento proativo diante de questões que precisam ser resolvidas.

O empreendedorismo é o despertar do indivíduo para o aproveitamento integral de suas potencialidades racionais e intuitivas. É a busca do autoconhecimento em processo de aprendizado permanente, em atitude de abertura para novas experiências e novos paradigmas.

Empreendedorismo [3], é um processo de “destruição criativa", através da qual produtos ou métodos de produção existentes são destruídos e substituídos por novos. Já para [4] corresponde a um o processo de transformar sonhos em realidade e em riqueza. Para [5] "empreendedorismo é habilidade de criar e constituir algo a partir de muito pouco ou de quase nada". É o desenvolver de uma organização em oposição a observá-la, analisá-la ou descrevê-la.

Segundo [6] empreendedor é aquele que detecta uma oportunidade e cria um negócio para capitalizar sobre ela, assumindo riscos calculados. Em qualquer definição de empreendedorismo encontram-se, pelo menos, os seguintes aspectos referentes ao empreendedor: 1) tem iniciativa para criar um novo negócio e paixão pelo que faz; 2) utiliza os recursos disponíveis de forma criativa, transformando o ambiente social e econômico onde vive; 3) aceita assumir os riscos calculados e a possibilidade de fracassar.

Para [7] espírito empreendedor é a energia da economia, a alavanca de recursos, o impulso de talentos, a dinâmica de ideias. Mais ainda: ele é quem fareja as oportunidades e precisa ser muito rápido, aproveitando as oportunidades fortuitas, antes que outros aventureiros o façam. O empreendedor é a pessoa que inicia e/ ou opera um negócio para realizar uma ideia ou projeto pessoal assumindo riscos e responsabilidades e inovando continuamente.

\section{BIOJOIAS}

Não há um consenso sobre a definição de Biojoia. Alguns especialistas definem como adornos que associam materiais naturais e materiais nobres. Porém, pode ser chamada Biojoia qualquer acessório de moda como colares, brincos, pulseiras, entre outros, produzidos a partir de matéria-prima natural como sementes, fibras, coco, madeira, etc.

Entre os principais acessórios produzidos podem ser destacados os auriculares, cintos, colares, braceletes, peitorais, braçadeiras, pulseiras, tornozeleiras, bolsas, entre outros diversos. 
A Biojoia é um acessório produzido a partir da união de elementos naturais, tais como sementes diversas, fibras naturais, casca do coco, conchas, madrepérola, capim, madeira, ossos, penas, escamas, etc., com ouro, pedras preciosas, semipreciosas e outros materiais nobres.

As biojoias são joias feitas artesanalmente com sementes colhidas na floresta, beneficiadas e imunizadas pelos índios, seringueiros, colonos e ribeirinhos da região, onde, repassadas para os artesões locais, tornam-se através de fino acabamento em maravilhosas peças.

As biojoias são produzidas por artesãos, mas já existe no mercado o profissional definido como Biodesigner, que assessora o artesão tanto para que a busca por insumos na natureza se realize dentro de parâmetros de responsabilidade ambiental quanto na orientação em relação aos cuidados necessários para que as biojoias tenham qualidade e durabilidade. [1].

O mercado de biojoias está em expansão com potencial de exportação. A demanda pela comercialização de biojoias vem crescendo a cada dia devido à atratividade que elas possuem com sua beleza e originalidade.

A produção de Biojoias teve início na Amazônia e difundiu-se pelo país ganhando espaço tanto no mercado interno, bem como na exportação de peças para diversos países, dentre eles: Itália, Estados Unidos, Espanha, Alemanha, valorizando cada vez mais a arte naturalizada.

Apesar de a maior parte das biojoias serem produzidas em determinadas regiões do Brasil, onde há comunidades que se beneficiam da atividade, gerando emprego e renda, as biojoias hoje são produzidas e comercializadas em praticamente todo o território nacional. São muitas as pesquisas feitas para entender o mercado consumidor de biojoias.

Por exemplo, ao pesquisar sobre o canal de comercialização dos produtos florestais não madeireiros em comunidades ribeirinhas da Amazônia, verificaram que as biojoias atendem principalmente ao mercado internacional. Isso principalmente devido ao valor agregado que produtos autênticos de comunidades da Amazônia têm para esses compradores [8].

No mercado internacional é crescente o sucesso das biojoias brasileiras e os produtos naturais são bastante valorizados no mercado externo. A diversidade e beleza das peças produzidas no Brasil, aliadas à criatividade do brasileiro, enchem as vitrines das lojas de "Tropic Concept" (um conceito adotado pelas lojas estrangeiras ao se referirem às biojoias brasileiras, que possuem uma conotação tropical). Empreendedores de biojoias da cidade de Ribeirão Preto/SP alegam que $90 \%$ da produção daquela região é adquirida por estrangeiros.

Enfim, é notório que após uma ampla divulgação de conceitos como preservação, desenvolvimento sustentável etc., as pessoas buscam alternativas que possam contribuir positivamente com o meio-ambiente. Segundo [8], o crescimento da conscientização ambiental das pessoas tem contribuído para uma maior valorização de atividades que envolvam o conceito de sustentabilidade, onde as biojoias podem ser consideradas uma amostra da biodiversidade das florestas, por isso possui alto valor agregado e grande aceitação no mercado.

A tendência de utilizar acessórios feitos com elementos da floresta se expandiu no Brasil durante a década de 1990 e hoje eles são constantes nos desfiles nacionais e principalmente internacionais, gerando oportunidades de emprego e renda para as pessoas que têm a habilidade em produzi-los, além de o artesão poder ter seu próprio negócio.
As sementes mais adequadas para a fabricação de biojoias são as maduras que não germinam, catadas no solo da floresta. Dentre as sementes utilizadas, destaca-se: O Tucumã ou Tucum-Açu, fruto original dos estados do Acre, Amazonas, Pará e Rondônia. Nesse caso, a semente chega a ser tão resistente quanto um metal. À semente beneficiada são juntados materiais nobres como o ouro e a prata ou outros retirados da floresta e rios, como resíduos madeireiros, fibras de carauá, fibras de miriti e escama de peixe.

\section{III.1 CARACTERIZAÇÃO DA BIOJOIA}

A biojoia é um adorno produzido a partir de elementos naturais, como sementes, fibras naturais, casca de coco, frutos seco, conchas, ossos, penas, entre outros. Além disso, durante o processo de produção, matéria-prima natural é extraída de forma sustentável e por isso não agride o meio ambiente.

O desenvolvimento de negócios sustentáveis provém da consciência dos líderes que estão à frente dos empreendimentos, além de uma sociedade cada vez mais consciente com o meio ambiente. A Biojoia não é um segmento novo, mas vem ganhando cada vez mais espaço desde que o mundo vem valorizando os produtos que, além de gerar lucro, sejam ecológicos e socialmente corretos.

De acordo com [9] por mais paradoxal que possa parecer, o galopante processo de globalização valorizou o fazer manual. $\mathrm{O}$ artesanato, hoje, é a contrapartida à massificação e à uniformização de produtos globalizados, promovendo ao mesmo tempo o resgate cultural e a identidade regional.

Observando esta abertura de mercado artesãos, designers e empresas aproveitam para inserir novos produtos neste segmento, que apresenta uma abordagem diferenciada dada a utilização de materiais que exigem processos especiais em toda a cadeia produtiva. É indispensável o cuidado na definição de tais processos e técnicas de trabalho com sementes, para que não seja alterada nenhuma das características que tornam estes materiais o principal diferencial percebido no segmento.

As sementes hoje deixaram de ser utilizadas apenas pelo artesanato local. No Brasil elas aparecem aplicadas a acessórios nos grandes desfiles de moda nacional e são exportadas para todo o mundo. Segundo [9]: "De início relacionada à história natural e à etnografia, as sementes ultrapassaram os limites dos herbários e do artesanato tradicional, atingindo uma beleza de caráter universal. Apesar da sua transfiguração de semente exótica em joia cosmopolita (...) ela conserva ainda o mistério de suas origens na sua própria textura. Não importa o quão longa ou sofisticada possa ter sido sua trajetória dos igarapés às vitrines de Paris ou Viena, ela conserva uma mística original, uma textura exótica, cujo cerne é impossível de ser destituído."

A Biojoia é um produto que une a matéria-prima original do território brasileiro e a moda, ampliando a gama de produtos que são considerados ecologicamente corretos, lembrando também que a atividade artesanal é fonte de geração de renda para muitas famílias no Brasil.

$\mathrm{O}$ artesanato com sementes se expande a cada ano, sendo possível encontrá-lo em grande escala no mercado, contribuindo para a valorização do produto com certificação, e também para inovações no setor aplicadas as tecnologias e novos processos produtivos.

Com a ampla oferta de matéria-prima, a produção de Biojoia no Brasil é crescente, mas ainda há grande dificuldade em encontrar fornecedores que ofereçam o material com qualidade, além de pesquisas que apresentem informações referentes à sua melhor conservação. 
Segundo [10], sob um ponto de vista mais geral, presenciamos um balanço totalmente desequilibrado entre o serviço oferecido por um produto e o conjunto de seus impactos.

Para analisarmos a cadeia de valor da Biojoia, foram utilizados os requisitos gerais apresentados por [11] para que seja possível avaliar a coerência com os princípios da sustentabilidade. De acordo com os autores um produto deve:

1-) Basear-se fundamentalmente em recursos renováveis.

2-) Otimizar o emprego de recursos não renováveis.

3-) Não acumular lixo que o ecossistema não seja capaz de renaturalizar.

4-) Agir de modo com que cada indivíduo, e cada comunidade das sociedades "ricas" permaneça nos limites do seu espaço ambiental e, que cada indivíduo e comunidade das sociedades "pobres" possam efetivamente gozar do espaço ambiental ao qual potencialmente têm direito.

\section{TUCUMÃ}

Fruto da família Arecaceae, também conhecido como tucumã-do-amazonas e tucumãaçu, é uma palmeira de grande importância socioeconômica para os povos da Amazônia. A polpa do seu fruto pode ser consumida ao natural, como recheio de pães ou tapiocas, ou usada no preparo de sorvetes, suco, licor, creme, patês e pratos quentes, muito apreciados pela população regional e pelos turistas.

Das sementes e da polpa dos frutos também podem ser extraídos óleos comestíveis para uso na suplementação alimentar humana e na fabricação de ração animal. O endocarpo (camada mais interna do pericarpo dos frutos, que se acha em contato com a(s) semente(s), de constituição bastante variável, como, p.ex., o caroço da azeitona e a parte comestível da laranja; endocárpio) é empregado na fabricação de artesanatos e na indústria de biojoias.

Os poucos estudos sobre o cultivo dessa espécie e a inexpressiva ocorrência de áreas plantadas fazem com que praticamente toda a produção para abastecimento do mercado seja proveniente do extrativismo. A dificuldade de germinação das sementes e a impossibilidade da propagação vegetativa da espécie têm sido apontadas como os principais fatores limitantes ao seu cultivo.

Em condições naturais, o tucumã leva de dois até três anos para germinar. Contudo, essa dormência pode ser minimizada pela retirada do endocarpo após a secagem da semente [12] e pela embebição das sementes em água [13].

Usa-se o caroço do fruto para fazer anéis, pulseiras, colares, peteca e bichos (besouro). As joias de tucumã não são apenas enfeites, elas também são usadas como proteção contra doença e mal olhado pelos nativos da floresta, segundo os nativos da região.

A transformação da semente do tucumã para biojoia, passa pelo seguinte processo: os caroços ficam durante sete (7) dias secando ao sol, até estarem completamente secos, em seguida, passam pelo polimento de várias lixas e a cortagem. Na sequência, entram no processo da coloração, os caroços são depositados em uma panela no fogo e as cores vão sendo inseridas, de acordo com as tendências da moda, dentro da ótica do artesão.

A partir desse ponto, o artesão elabora os modelos de joias que comercializará. Sempre buscando as tendências do mercado.
V. MATERIAIS E MÉTODOS

\section{V.1 PUBLICO ALVO DA PESQUISA}

A presente pesquisa foi desenvolvida com 52 artesões da Associação da feira de artesanato e produtos do amazonas, localizado na Feira de Artesanato da Avenida Eduardo Ribeiro, Centro de Manaus-AM (Figuras 1 e 2).

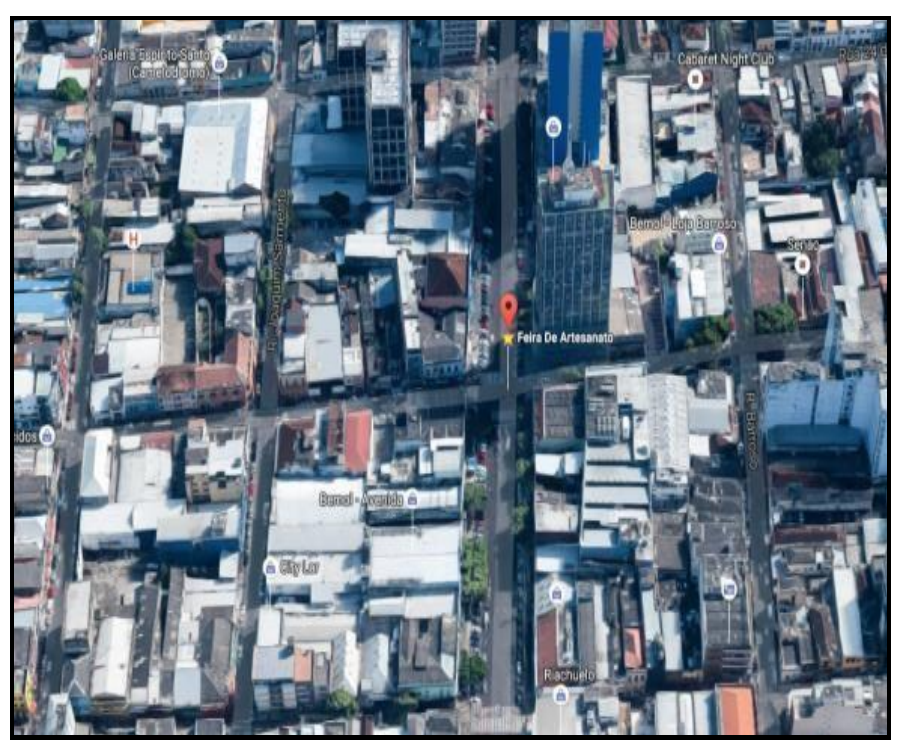

Figura 1: Localização Geográfica da Pesquisa.

Fonte: [14].

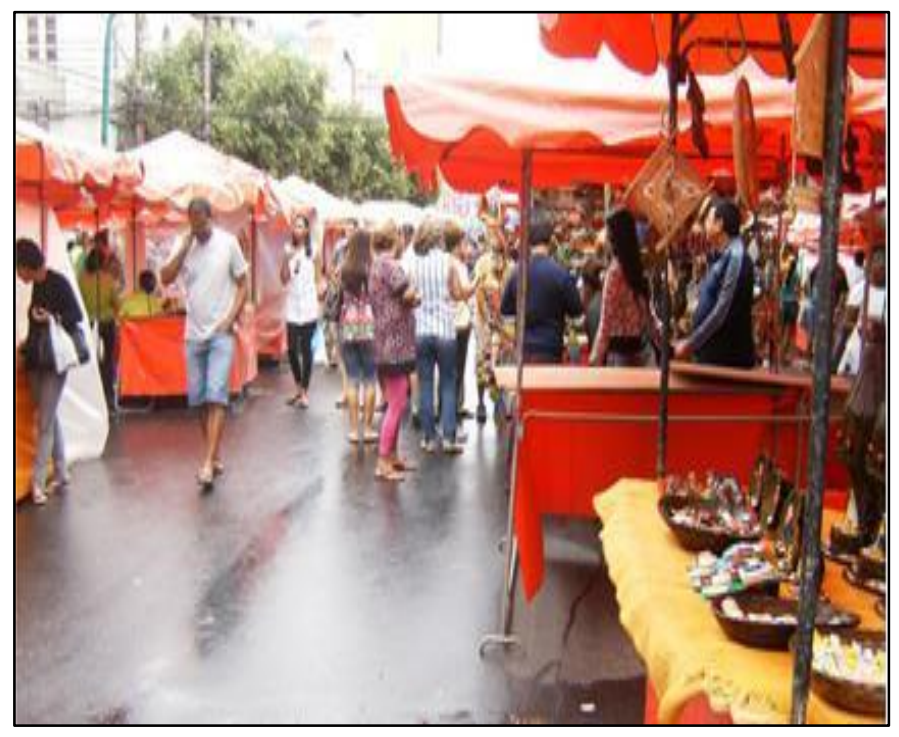

Figura 2: Feira dos Artesões.

Fonte: Autores, (2017).

Toda pesquisa de campo requer uma investigação ampla e detalhada e nesse sentido esta foi realizada in loco onde, estão os produtores de biojoias. Este procedimento se deu por meio de aplicação de um questionário contendo 14 questões semi estruturadas, produzidas pela própria pesquisadora e também por meio de uma observação participante (figura 3 e 4) para assim, verificarmos as vantagens dessa atividade, o processo de confecção da biojoia e o rentabilidade da mesma. 


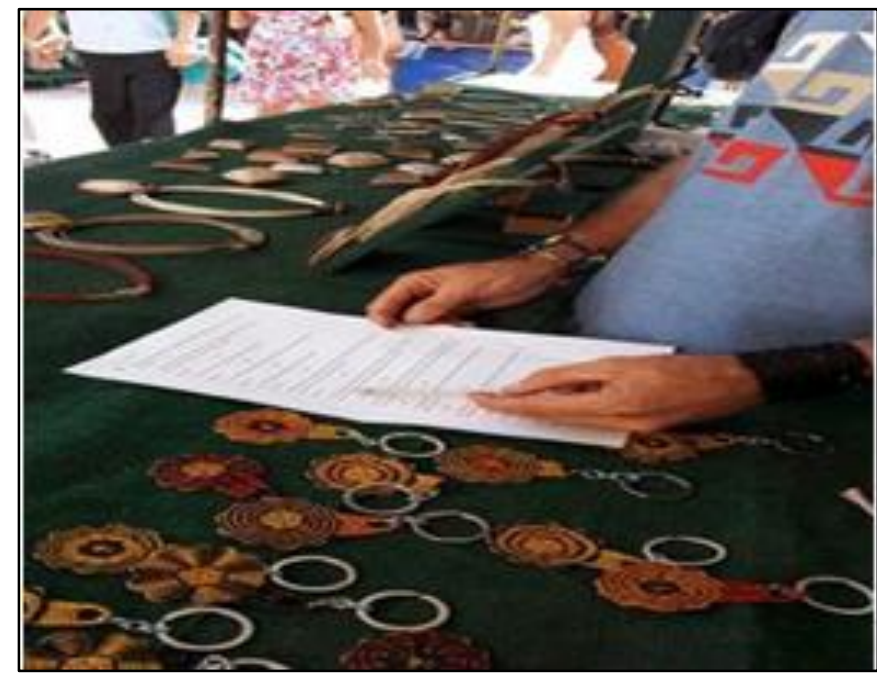

Figura 4: Aplicação de questionário.

Fonte: Autores, (2017).

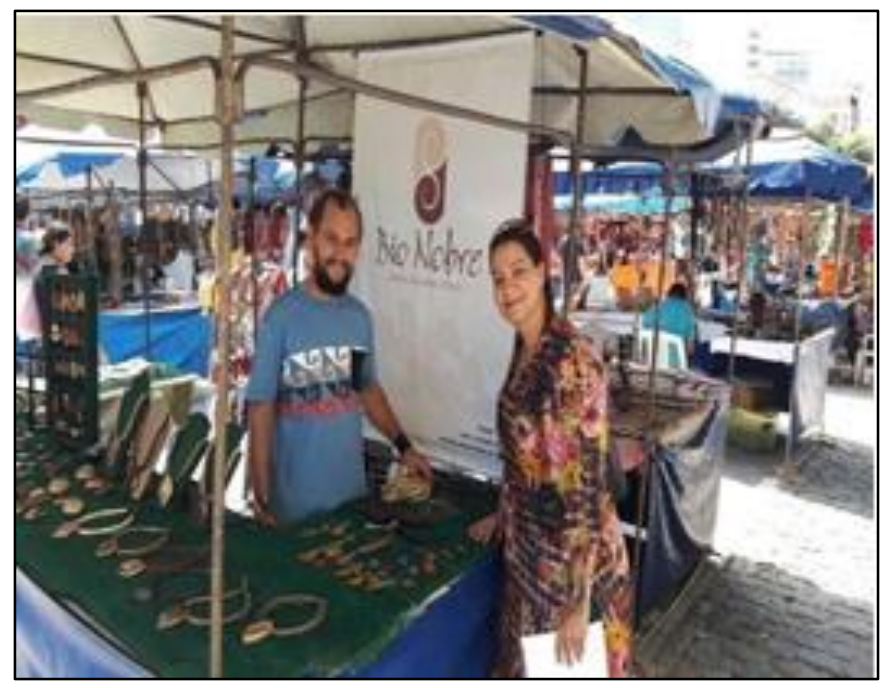

Figura 5: Observação Participante.

Fonte: Autores, (2017).

Nesta etapa (acima) de aplicação de questionário e observação participante serviu-nos dentre outros para demonstrar como o empreendedor pode gerar a partir da transformação da semente do tucumã em biojoia, uma oportunidade de negócio, também para conhecermos a visão desses artesoes sobre suas contribuições para com o meio ambiente através de suas atividades.

A biojoia é um adorno produzido a partir de elementos naturais, como sementes, fibras naturais, casca de coco, frutos secos, conchas, ossos, penas, entre outros. O estudo em tela é a semente do tucumã. As sementes devem ser submetidas a um processo de eliminação de fungos e parasitas para posteriormente serem embaladas a vácuo e etiquetadas. Além disso, durante o processo de produção, a matéria-prima natural é extraída de forma sustentável e por isso não agride o meio ambiente.

\section{V.2 CONFECÇAO DAS BIOJOIAS - PASSO A PASSO}

A classificação do projeto de pesquisa quanto à sua abordagem é considerada quantiqualitativa, pois procurou demonstrar as vantagens e viabilidade da pratica de biojoias com a utilização do caroço de tucumã por artesões da cidade de Manaus-AM.

Importante ressaltar que o ambiente natural é a fonte direta para coleta de dados e o pesquisador é o instrumentochave. Desse modo, visou-se descrever as características das biojoias feitas pelos artesãos da Feira de Artesanato da Avenida Eduardo Ribeiro, em Manaus, AM, que tiram da floresta a matéria prima para a confecção dos referidos artefatos.

Esta pesquisa foi dividida em etapas, a saber: A coleta e a separação dos matérias é importante porque é o primeiro passo para o beneficiamento dos caroços na produção dos artesanatos. $\mathrm{O}$ beneficiamento das sementes para o artesanato é realizado com a utilização de equipamentos que vão desde ferramentas manuais, materiais rústicos adaptados e movidos à eletricidade como polideiras e furadeiras conforme mostra as figuras $6,7,8,9,10,11$.

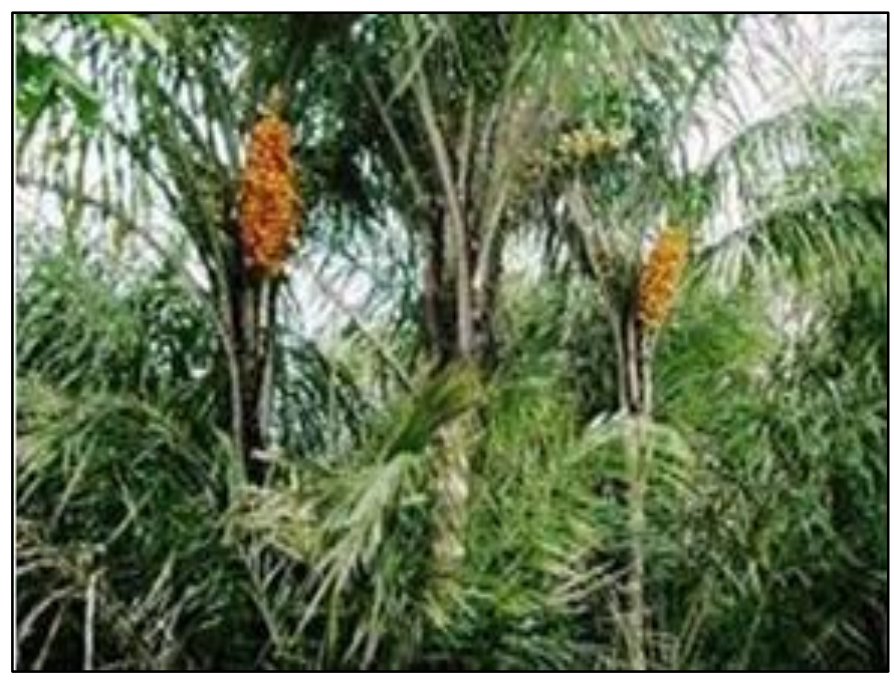

Figura 6: Coleta do Tucumã.

Fonte: Autores, (2017).

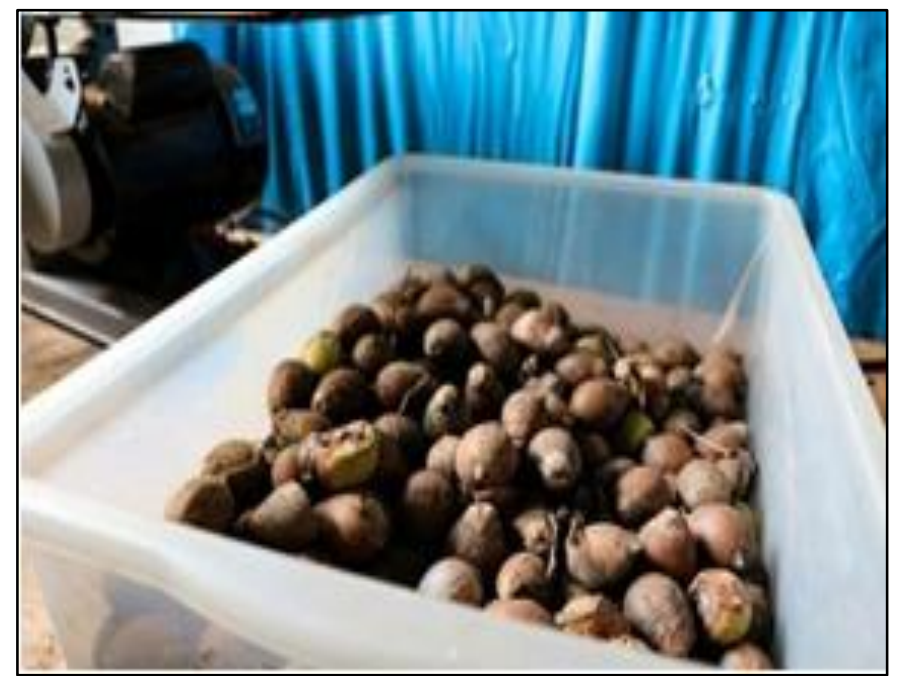

Figura 7: Separação dos Caroços Tucumã.

Fonte: Autores, (2017). 


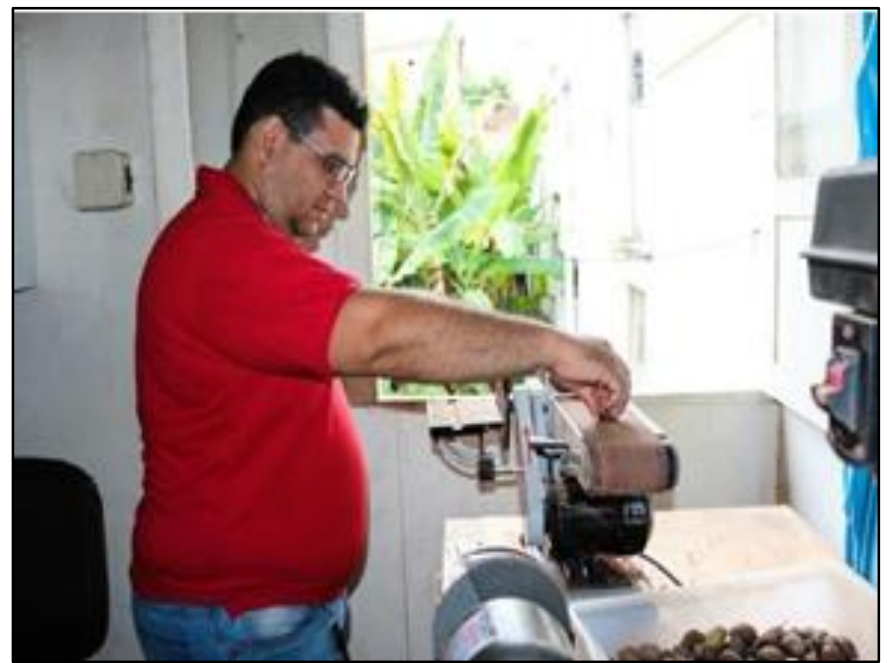

Figura 8: Cortes dos caroços para Lixamento. Fonte: Autores, (2017).

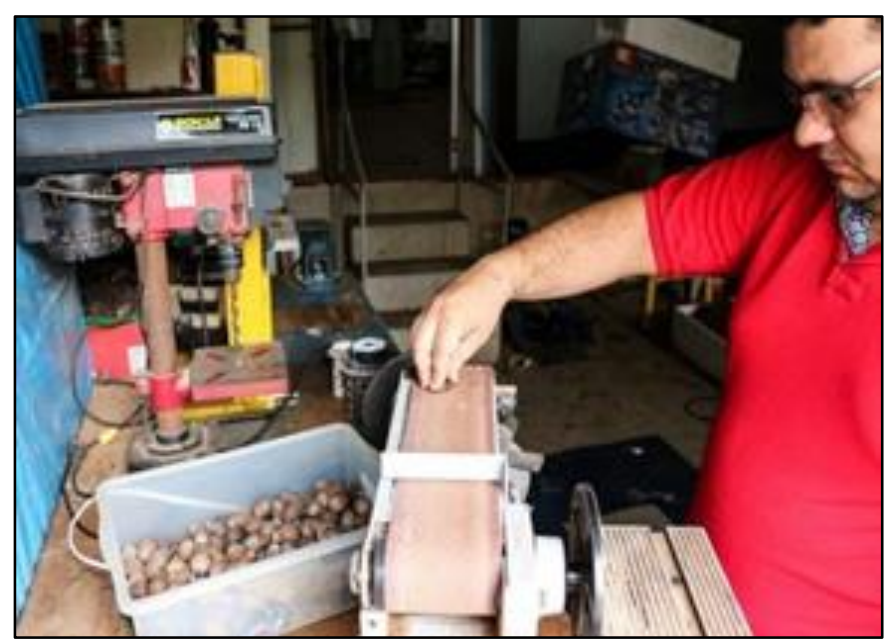

Figura 9: Lixamento e Selagem dos Caroços.

Fonte: Autores, (2017).

Após estas etapas acima descritas, os caroços estão prontos para o beneficiamento e confecção dos produtos. Conforme as figuras 10 e 11.

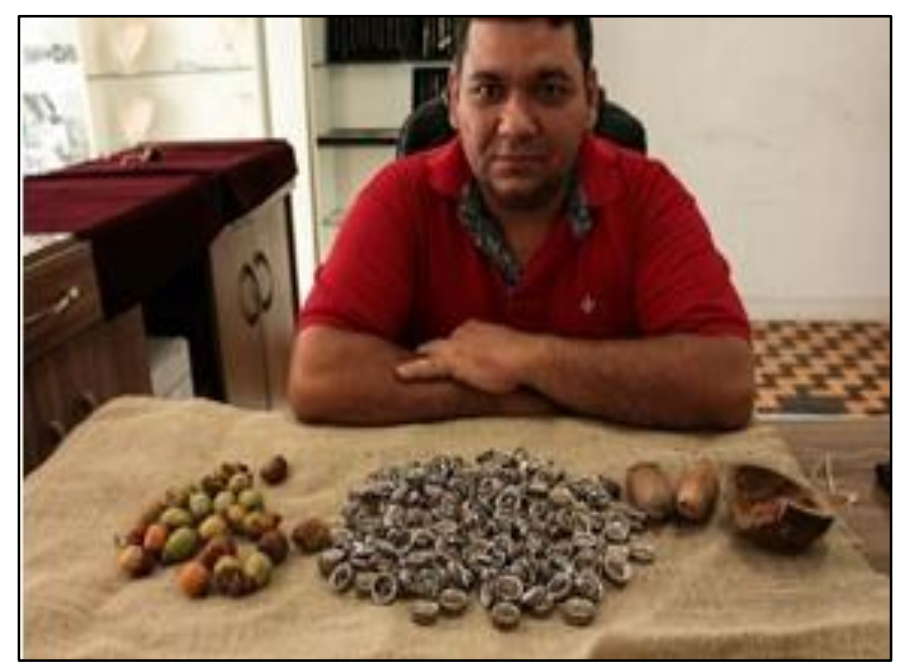

Figura 10: Peças para confecção das biojóias.

Fonte: Autores, (2017).

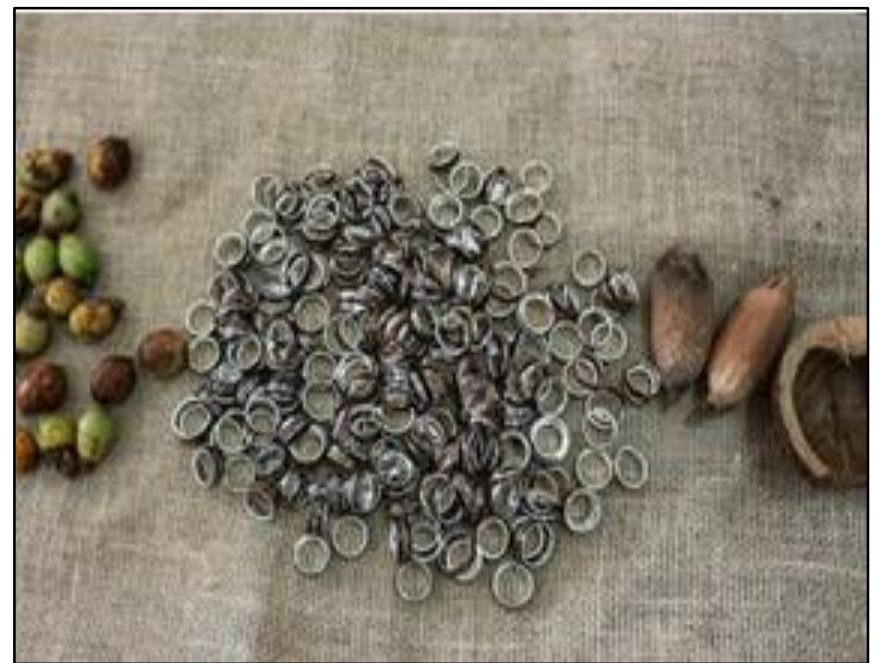

Figura 11: Peças de prata com tucumã.

Fonte: Autores, (2017).

\section{V.3 PRODUÇAO COMPLETA DAS BIOJOIAS}

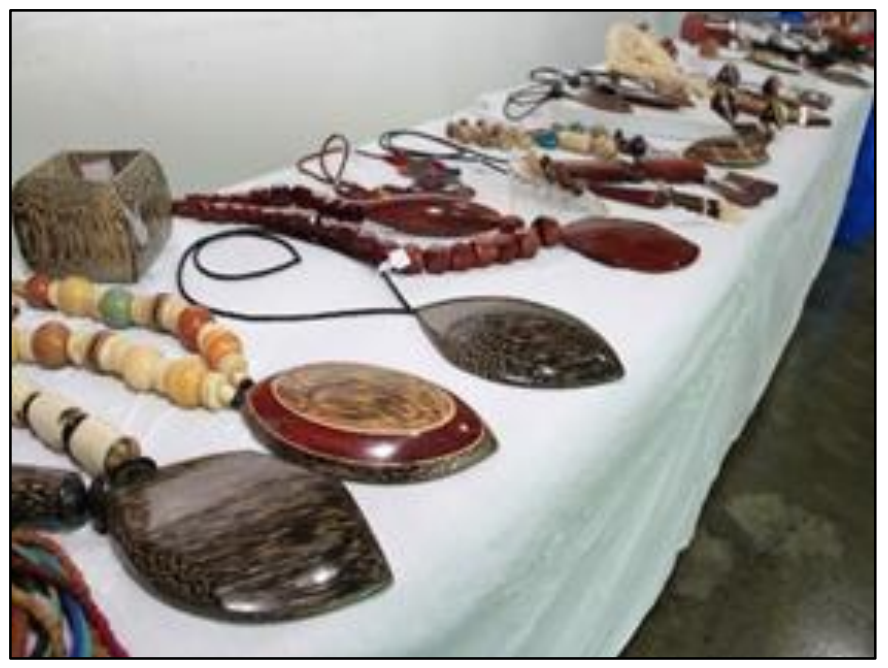

Figura 12: Peças prontas.

Fonte: Autores, (2017).

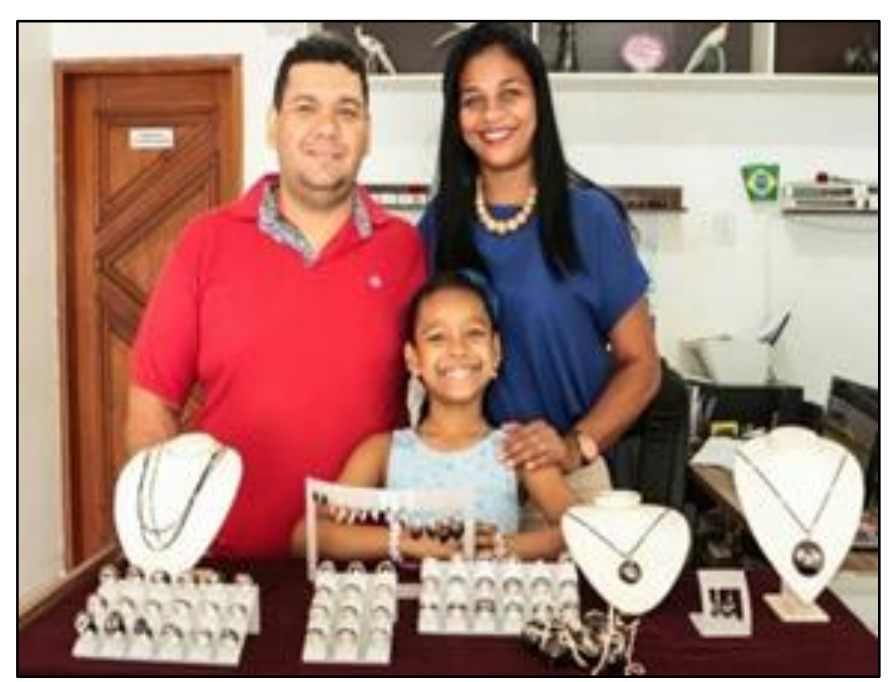

Figura 13: Peças prontas com prata e tucumã. Fonte: Autores, (2017).

VI. ANALISE E DISCUSSÕES DOS RESULTADOS 
Nesta etapa da pesquisa foi possível analisar os materiais coletados e transforma-los em dados estatísticos para uma melhor compreensão dos mesmos.

Quando questionados sobre a importância das biojoias no processo de desenvolvimento local, $96 \%$ dos entrevistados foram contundentes ao afirmar que esta atividade contribui de forma significativa para o desenvolvimento local, pois, os ajuda com mais da metade da renda familiar e ainda contribui para a manutenção e preservação do meio ambiente local. (Figura 14).

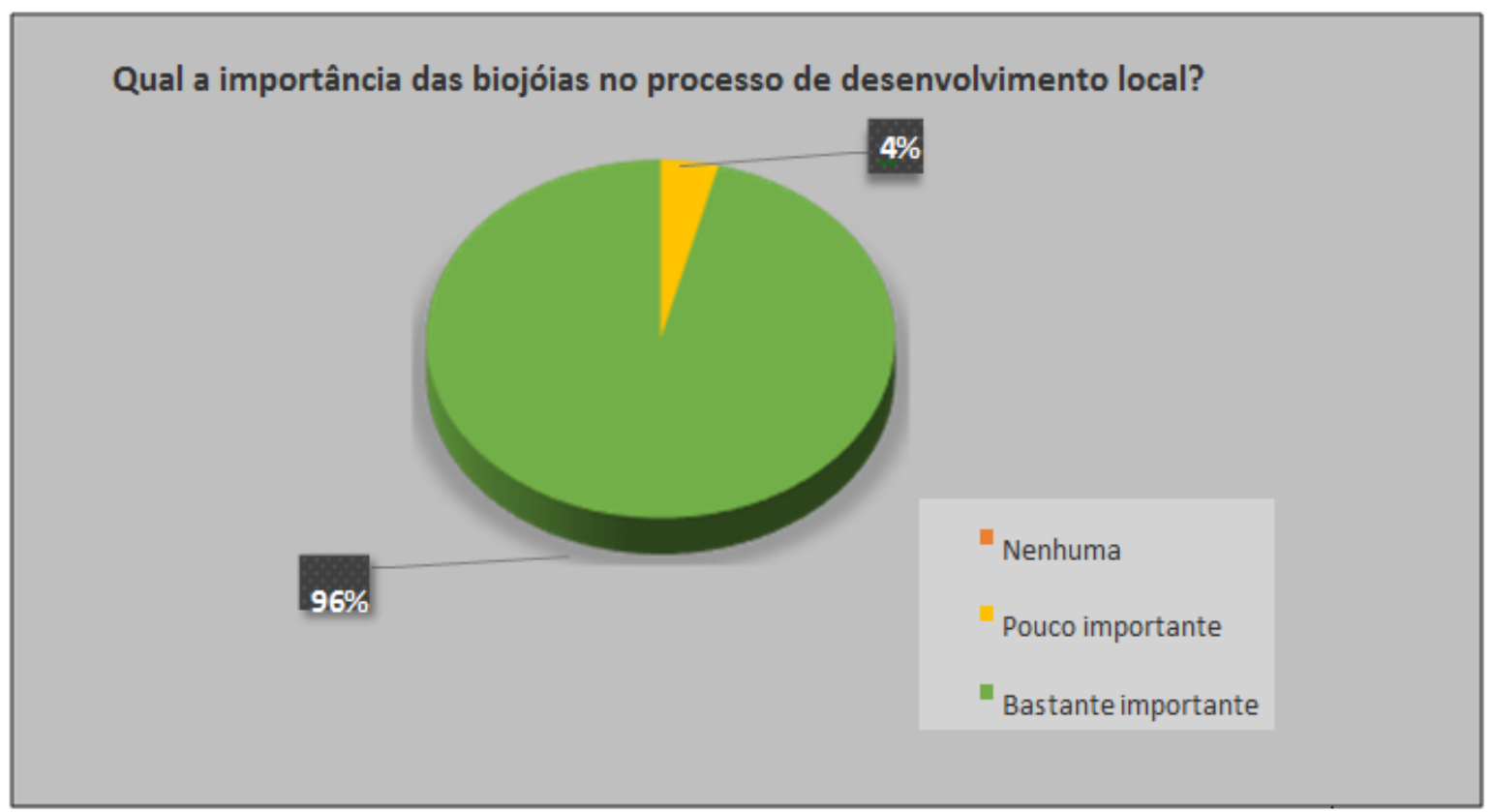

Figura 14: Qual a importância das biojoias no processo de desenvolvimento local?

Fonte: Autores, (2017).

Quando os participantes da pesquisa foram perguntados sobre a porcentagem mensal (lucros) que um artesão local consegue com o trabalho das biojoias 40 dos 52 pesquisados responderam que conseguem um lucro acima de $70 \%$ mensal, exemplificando o quanto é vantajoso, lucrativo, prazeroso e importante o trabalho de um artesão, pois, ao mesmo tempo que desenvolve seu trabalho de forma lucrativa, contribui de forma positiva com o meio ambiente local. (Figura 15).

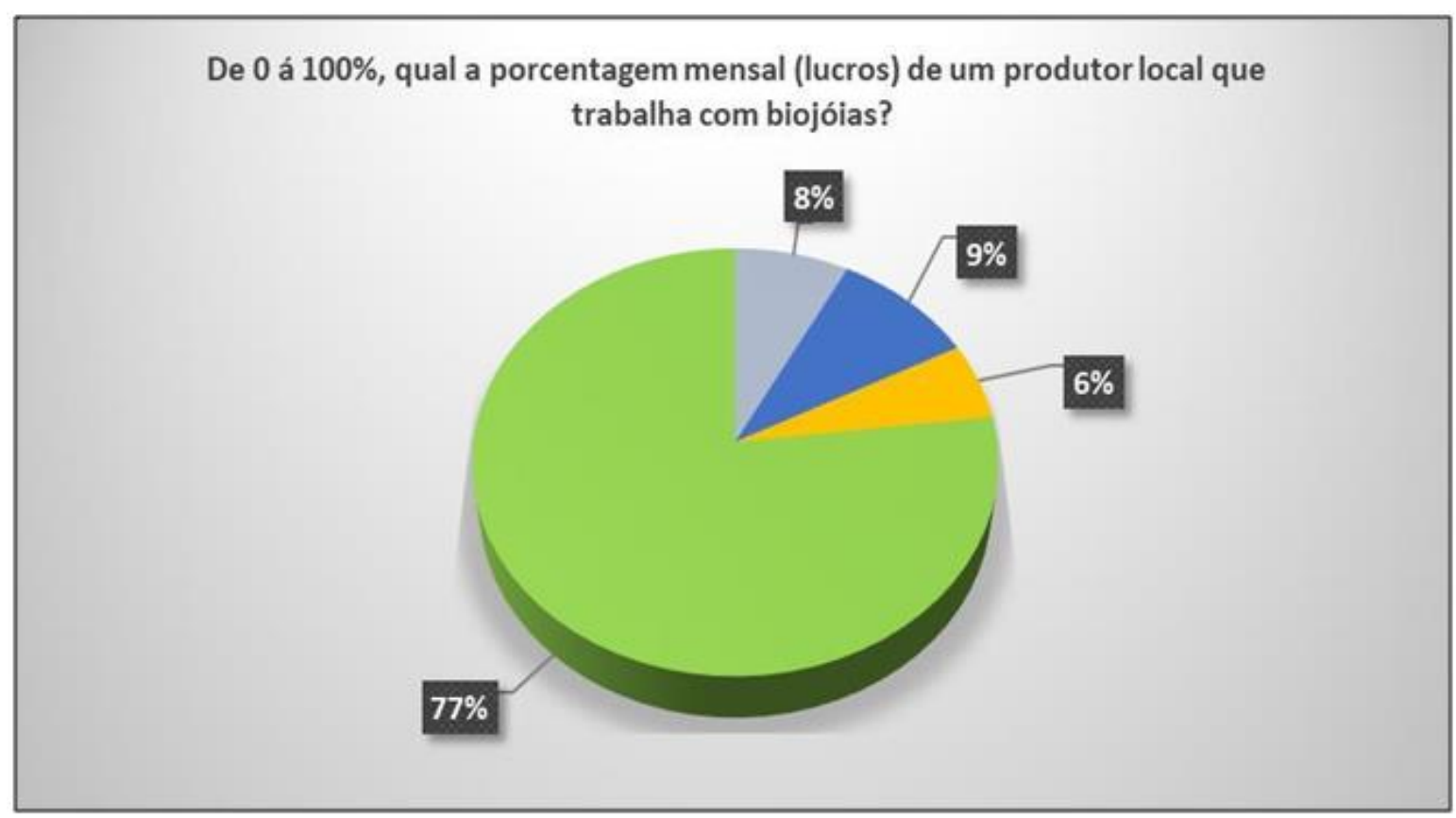

Figura 15: Qual a porcentagem mensal (lucros) de um produtor local que trabalha com biojoias?

Fonte: Autores, (2017).

Os pesquisados também foram questionados sobre a importância do seu trabalho para a valorização, desenvolvimento e preservação da cultura local. Com o processo de análise pôde-se perceber que $62 \%$ dos entrevistados responderam que utilizam as imagens que representam a cultura indígena local, já $36 \%$ na maioria das vezes preferem utilizar imagens da fauna e flora da região e $2 \%$ utilizam imagens voltados para as comidas típicas da região.

Tudo isso pode ser verificado nas imagens dos seus produtos e assim, estes acreditam que seja uma forma de 
valorizar e preservar aquilo que é mais precioso dentro de um povo que é sua cultura local. (Figura 16).

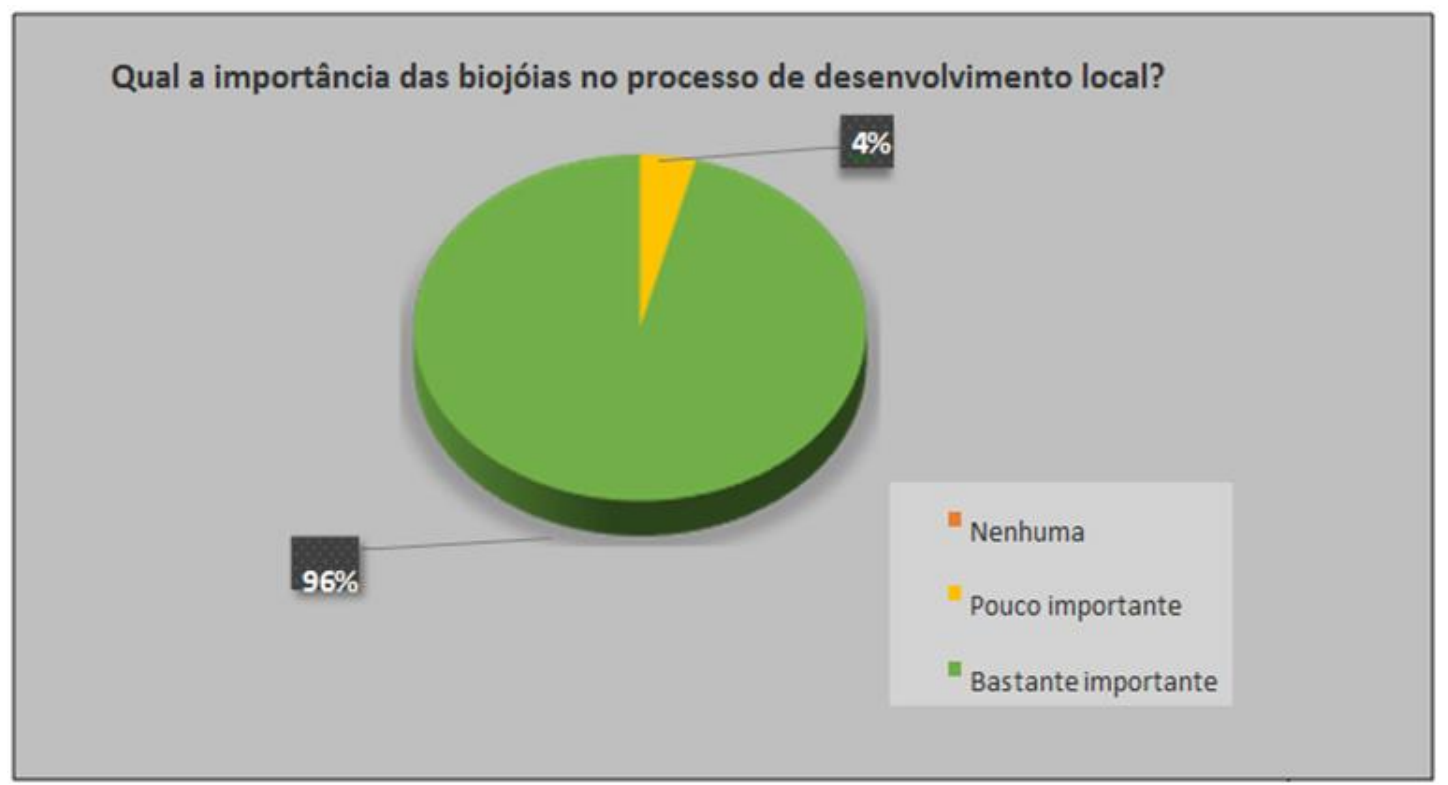

Figura 16: As biojoias feitas pelos artesoes visam a valorização da cultura local?

Fonte: Autores, (2017).

Nesse contexto, [9], ressalta que o desenvolvimento de negócios sustentáveis provém da consciência dos líderes que estão à frente dos empreendimentos, além de uma sociedade cada vez mais consciente com o meio ambiente.

A Biojoia não é um segmento novo, mas vem ganhando cada vez mais espaço desde que o mundo vem valorizando os produtos que, além de gerar lucro, são ecológicos e socialmente corretos.

Ainda de acordo com [9] por mais paradoxal que possa parecer, o galopante processo de globalização valorizou o fazer manual. $\mathrm{O}$ artesanato, hoje, é a contrapartida à massificação e à uniformização de produtos globalizados, promovendo ao mesmo tempo o resgate cultural e a identidade regional.

Assim sendo, é indispensável o cuidado na definição de tais processos e técnicas de trabalho com sementes, para que não seja alterada nenhuma das características que tornam estes materiais o principal diferencial percebido no segmento.

\section{CONSIDERAÇÕES FINAIS}

Com os resultados obtidos através da aplicação do questionário e observação participante, pode-se comprovar que a produção de Biojoias torna-se a cada dia uma atividade lucrativa e rentável para a população que desenvolve essas atividades na região de Manaus e isso pôde ser comprovado com os dados estatísticos onde $92 \%$ dos pesquisados afirmaram que conseguem uma renda acima de $70 \%$ mensal para sustento da família.

Assim, observou-se que o trabalho desenvolvido com o caroço de tucumã utilizado como matéria-prima para confecção de artefatos e produtos do setor de joalheria, além da facilidade e baixo custo na produção das peças, contribui com a atualização da moda, aceita mistura de materiais alternativos de origens diversas, ainda traz benefícios ao meio ambiente.

Dessa forma, verificou-se o quanto é essencial, prazeroso e lucrativo a confecção de biojoias na cidade de Manaus-AM, pois, além de contribuir com o crescimento local, valorização cultural, ainda contribui de forma significativa com o desenvolvimento sustentável da região.

\section{REFERÊNCIAS}

[1] Souza, Paulo Augusto Ramalho de; Fragata, Juliane Pinheiro; Assis, Carla Alexandra Rodrigues; Canto, Delana Souza. Empreendedorismo e Desenvolvimento Local: O Caso da Produção de Biojoias na Amazônia. Manaus/Cuiabá: Universidade Federal do Amazonas/ Universidade Federal de Mato Grosso, 2014. Disponível em: <http://www.eumed.net/rev/cccss/20/sfac.html>. Acesso em: 17 jun. 2017.

[2] Moreira, Janaina Lorena; Lima, Laisy Garcia Ribeiro; Tótaro, Leila Said. Empreendedorismo sustentável: o valor de Negócios ambientais. e-xacta, Belo Horizonte, v. 6, n. 2, p. 177-189. (2014). Editora UniBH. Disponível em: <http.unibh.br/revistas/exacta/.> Acesso em: 25 ago. 2015.v

[3] Schumpeter, J. A. A teoria do desenvolvimento econômico. São Paulo: Nova Cultura, 1988.

[4] Dolabela, F. O segredo de Luisa. São Paulo: De Cultura, 2010 .

[5] Barreto, L. P. Educação para o empreendedorismo. São Paulo: Educação Brasileira, 1998.

[4] Dornelas, J. C. A. Empreendedorismo: transformando ideias em negócios. Rio de Janeiro: Elsevier, 2008.

[7] Chiavenato, I. Empreendedorismo: dando asas ao espírito empreendedor. São Paulo: Saraiva, 2004.

[8] Faria, Lívia Mara Siqueira. Implantação de espécies Arbóreas, Herbáceas e Trepadeiras para a sustentabilidade de Biojoias como modelo de reflorestamento. Trabalho de conclusão de curso de Gestão Ambiental, do Instituto Federal de Educação, Ciência e Tecnologia, Campus Inconfidentes, $2009 . \quad$ Disponível em:< href="http://www.ifs.ifsuldeminas.edu.br" >www.ifs.ifsuldemin as.edu.br>. Acesso em: 26 ago. 2015 
[9] Bandeira, Julio Sementes ornamentais do Brasil. Rio de Janeiro: Reler, 2008. DIAS, Genebaldo Freire. Pegada Ecológica e Sustentabilidade Humana. São Paulo: Gaia, 2006.

[10] Kazazian, Thierry. Haverá a idade das coisas leves. São Paulo: Editora Senac São Paulo, 2008.

[11] Vezzoli, Carlo. MANZINI, Ezio; O Desenvolvimento de produtos sustentáveis. São Paulo: Editora da Universidade de São Paulo, 2009 O Desenvolvimento de produtos sustentáveis. São Paulo: Editora da Universidade de São Paulo, 2009

[12] Miranda, I. P. A. et al. Frutos de palmeiras da Amazônia. Manaus: MCT/INPA, 2011.

[13] Ferreira, S. A. N.; Gentil, D. F. O. Extração, embebição e germinação de sementes de tucumã Astrocaryum aculeatum. Acta Amazônica, v. 36, n. 2, p. 141-146, 2006.

[14] www. Google Earth. Elaborado por Menezes, P. Acessado em 21.09.2017.

[15] ABNT - Associação Brasileira de Normas Técnicas. 